\title{
ANALISIS KEPUTUSAN PEMBELIAN BERDASARKAN PROMOSI DAN CITRA MEREK
}

\section{ANALYSIS OF PURCHASE DECISIONS BASED ON PROMOTION AND BRAND IMAGES}

\author{
Rafika Zubaydah \\ ${ }^{1}$ Pascasarjana Ilmu Ekonomi, Fakultas Ekonomi dan Bisnis, Universitas Sumatera Utara \\ vikazu2909@gmail.com
}

\begin{abstract}
ABSTRAK
Keputusan pembelian merupakan sikap konsumen untuk membeli atau tidak membeli produk yang ditawarkan perusahaan. Keputusan membeli dipengaruhi oleh banyak faktor terutama oleh faktor promosi dan citra merek. Dengan adanya promosi yang baik, diharapkan keputusan membeli juga semakin naik. Keputusan membeli juga dipengaruhi oleh citra merek yakni pandangan konsumen terhadap produk terkait dengan kualitas produk tersebut. Penelitian ini merupakan penelitian kuantitatif yang bertujuan untuk mengetahui pengaruh antara variabel yakni pengaruh promosi dan citra merek terhadap keputusan pembelian produk. Populasi penelitian adalah para konsumen perusahaan dan penentuan sampel menggunakan rumus random sampling sehingga diperoleh 67 sampel penelitian. Analisis data dilakukan dengan analisis regresi linier berganda yang terdiri dari uji-t secara parsial dan uji-f secara simultan. Hasil penelitian memperlihatkan bahwa promosi berpengaruh terhadap keputusan pembelian produk perusahaan Hal ini diindikasikan oleh nilai bahwa $\mathrm{t}_{\text {-hitung }} \mathrm{X} 1(7.077)>\mathrm{t}$ tabel $_{\text {ta. }}$ (1.997) dan sig-p $(0.000)<0.05$. Citra merek berpengaruh keputusan pembelian konsumen pada produk perusahaan. Hal ini diindikasikan oleh nilai bahwa $t_{\text {-hitung }} \mathrm{X} 2$ (4.523) $>\mathrm{t}$-tabel $(1.997)$ dan sig-p (0.000) < 0.05. Promosi dan Citra merek berpengaruh terhadap keputusan pembelian para konsumen terhadap produk perusahaan. Hal ini diindikasikan oleh nilai $\mathrm{F}_{\text {-hitung }}$ (67.703) $>\mathrm{F}_{\text {tabel }}(3.14)$ dan sig-p $(0.00)<0.05$. Terdapat pengaruh variabel bebas terhadap variabel terikat sebesar $0.669 \times 100 \%=66.9 \%$. Kepada Perusahaan, disarankan untuk lebih memperhatikan aspek-aspek Promosi dan Citra merek agar keputusan Pembelian dapat lebih ditingkatkan.
\end{abstract}

Kata kunci : Promosi, Citra merek, Keputusan pembelian

\section{ABSTRACT}

Decision for purchasing is an attitude of customers to buy or no products offered by a company. It is influenced by some factors mainly by promotion and brand image. With better promotion, it is expected to also increase the decision for purchasding. Therefore, it can be known that decision of purchasing is influenced by the brand image as a view of customers related to the products offered by the company. It is a quantitative study aimed at determining the effect variables namely the influence of promotion and brand image of product purchasing decisions. Population of the study included company's consumers and the sampling was used the random sampling method so that 67 samples were obtained. The collected data were done by multiple linear regression analysis consisting of t-test partially and f-test simultaneously. The result of the study shown that 
P-ISSN $2580-7781$

E-ISSN 2615 - 3238

promotion has significant effect on the decision of purchasing products offered by a company. It is indicated by $t_{\text {-count }} X_{1}$ (7.077)> t-table (1.999) and sig-p $(0.000)<0.05$. Brand image has also significant efect on the decision of purchasing any product offered by a company. It is indicated by $t_{\text {-count }} X_{2}(4.523)>t$-table $(1.999)$ and sig- $p(0.000)<0.05$. Promotion and brand image have significantly effect on decision of purchasing any products offered by a company.it is indicated by $F_{- \text {count }}(67.703)>F_{\text {-table }}(3.14)$ dan sig- $p$ $(0.00)<0.05$.There is influence of free variable to dependent variable equal to0.669 $x 100 \%=66.9 \%$.I is suggesed to the management of ccmpany to pay more attention to aspects of promotion and brand image so that the decision of purchasing can be further improved.

Keywords : Promotion, Brand image and Decision of purchasing.

\section{PENDAHULUAN}

Dalam era persaingan usaha yang semakin kompetitif sekarang ini, setiap pelaku bisnis yang ingin memenangkan kompetisi dalam persaingan pasar akan memberikan perhatian penuh pada strategi pemasaran yang dijalankannya. Produk-produk yang dipasarkan dibuat melalui suatu proses yang berkualitas akan memiliki sejumlah keistimewaan yang mampu meningkatkan kepuasan konsumen atas penggunaan produk tersebut. Dengan demikian pelanggan mau dan rela untuk kembali menikmati apa yang ditawarkan oleh perusahaan dan menjadi pelanggan yang setia bagi perusahaan.

Produk-produk yang dipasarkan dibuat melalui suatu proses yang berkualitas akan memiliki sejumlah keistimewaan yang mampu meningkatkan kepuasan konsumen atas penggunaan produk tersebut. Dengan demikian pelanggan mau dan rela untuk kembali menikmati apa yang ditawarkan oleh perusahaan dan menjadi pelanggan yang setia bagi perusahaan.

Tujuan dari semua perusahaan berkeinginan menjadi winner dalam persaingan pasar yang ada. Karena apabila dapat memenangkan persaingan pasar yang ada, perusahaan dapat memiliki banyak konsumen yang akan berujung pada profit yang didapat, namun untuk memasarkan suatu produk yang dimiliki suatu perusahaan tidaklah mudah, karena kompetitor perusahaan yang ada juga akan memberikan perlawanan yang sulit dan keras untuk produk perusahaan tersebut.

Kepuasan pelanggan juga dapat terkait dengan tersedianya produk dipasar. Hal ini dapat diindentifikasi oleh konsumen melalui distribusi produk yang ditawarkan dipasar lebih mencerminkan adanya hubungan harmonis antara 
P-ISSN $2580-7781$

E-ISSN 2615 - 3238

perusahan dan konsumen dan itu memberikan dasar yang baik untuk melakukan pembelian ulang serta tercipta loyalitas pelanggan.

Keputusan pembelian adalah tindakan yang dilakukan konsumen untuk melakukan pembelian sebuah produk. Oleh karena itu, pengambilan keputusan pembelian konsumen merupakan suatu proses pemilihan salah satu dari beberapa alternatif penyelesaian masalah dengan tindak lanjut yang nyata. Setelah itu konsumen dapat melakukan evaluasi pilihan dan kemudian dapat menentukan sikap yang akan diambil selanjutnya. Dalam sebuah keputusan pembelian terdapat beberapa peran konsumen yaitu inisiator, influencer, decider, buyer, user. Perusahaan perlu mengenal peranan tersebut karena semua peranan mengandung implikasi guna merancang produk, menentukan pesan dan mengalokasikan biaya anggaran promosi serta membuat program pemasaran yang sesuai dengan pembeli (Swastha dan Handoko, 2011).

Penelitian ini bertujuan mengetahui keputusan pembelian konsumen berdasarkan kegiatan promosi dan citra terhadap merek alat tulis faber-castell pada PT Mentari Sinar Abadi.

\section{METODE PENELITIAN}

Penelitian ini dilakukan di kantor PT. Mentari Sinar Abadi, di jalan Burjamhal block-A no.14, Medan. Menurut Sekaran (2006:77) populasi mengacu pada sekelompok orang, kejadian, atau hal minat yang ingin peneliti investigasi. Populasi dalam penelitian ini adalah konsumen yang berjumlah sebanyak 205 orang.

Populasi adalah merupakan wilayah generalisasi yang terdiri dari obyek/subyek yang memiliki kuantitas dan karakteristik tertentu yang ditetapkan oleh peneliti untuk dipelajari dan kemudian ditarik kesimpulannya. Itulah definisi populasi dalam penelitian. Populasi pada penelitian ini adalah berjumlah 205 konsumen produk faber-castell pada PT. Mentari Sinar Abadi. Populasi diambil pada tahun 2017. Sampel adalah sebagian dari jumlah dan karakteristik yang dimiliki oleh populasi tersebut, ataupun bagian kecil dari anggota populasi yang diambil menurut prosedur tertentu sehingga dapat mewakili populasinya. 
P-ISSN 2580 - 7781

E-ISSN 2615 - 3238

Penentuan jumlah sampel yang diambil sebagai responden dengan menggunakan rumus slovin, sebagai berikut:

$\mathrm{n}=$ Jumlah sampel minimal

$$
\mathrm{n}=\frac{\mathrm{N}}{1+\mathrm{Ne}^{2}}
$$

$\mathrm{N}=$ Jumlah populasi

$\mathrm{E}=$ persentase kelonggaran penelitian karena kesalah pengambilan sampel.

Dengan mengunakan rumus tersebut maka diperoleh jumlah sampe sebagai berikut:

$$
\mathrm{n}=\frac{205}{1+205(0,4)^{2}}=67
$$

Jadi, jumlah sampel minimal yang diteliti adalah berjumlah 67 konsumen produk faber-castell pada PT. Mentari Sinar Abadi Medan. Untuk memperoleh 67 konsumen ini dari 205, maka penulis menggunakan teknik random sampling dimana penulis mengambil sampel dari populasi secara acak.

Sumber data dalam penelitian ini antara lain data yang bersumber dari PT Daya Mentari Sinar Abadi Medan, sampel yang diambil sebanyak 67 responden data yang diperoleh termasuk data sumber primer dan sumber sekunder yaitu:

1. Data Primer (primary)

2. Data Sekunder (library)

Metode pengumpulan data yang digunakan dalam penelitian ini adalah:

1. Penelitian Kepustakaan (Library Research)

2. Penelitian Lapangan

3. Angket (Kuisioner)

4. Observasi (Pengamatan)

Uji validitas digunakan untuk mengukur apakah data yang telah didapat merupakan data yang valid, dengan alat ukur yang digunakan selama penelitian yaitu kuesioner. Metode yang akan digunakan untuk melakukan uji validitas adalah dengan melakukakan korelasi antar skor butir pertanyaan dengan total skor konstruk atau variabel. Butir pertanyaan dikatakan valid apabila $\mathrm{r}$ hitung $>\mathrm{r}$ tabel. 


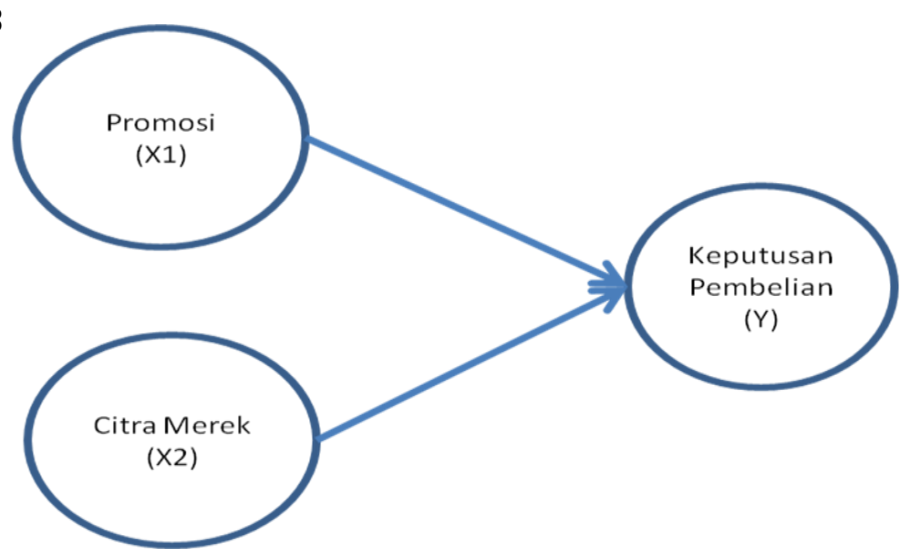

Gambar. 1: Kerangka Konsep Penelitian

Rumus yang digunakan untuk uji validitas konstruk adalah dengan teknik korelasi pearson product moment correlation Sugiyono (2010 : 172) yaitu :

$$
\text { rhitung }=\frac{\mathrm{n} \sum x y-\left(\sum x\right)\left(\sum y\right)}{\sqrt{\left[\sum x^{2}-\left(\sum x^{2}\right)\right]\left(n \sum y^{2}-\left(\sum y^{2}\right)\right]}}
$$

\section{Dimana:}

rhitung $=$ koefisien korelasi product moment

$\mathrm{X} \quad=$ skor variabel (jawaban responden)

$\mathrm{Y} \quad=$ skor total dari variabel untuk responden ke-n

Pengujian reliabilitas dilakukan secara internal. Sugiyono (2010:183) mengatakan bahwa: "Pengujian reliabilitas instrumen secara internal dapat dilakukan dengan menggunakan teknik belah dua kelompok (ganjil dan genap), ditotal, dicari korelasinya, dan kemudian dianalisis dengan rumus kofisien korelasi Spearman Brown. Uji reliabilitas dalam penelitian ini menggunkan SPSS 22 dengan uji statistik Cronbach Alpha. Suatu variabel dikatakan reliabel jika memberikan nilai Cronbach Alpha > 0,70 (Imam Ghozali, 2011).

Uji normalitas akan dideteksi melalui analisa grafik (PP-Plot) yang dihasilkan melalui perhitungan regresi dengan SPSS. Dasar pengambilan keputusan menurut Sarwono (2012:96) yaitu : Jika data menyebar sekitar garis diagonal dan mengikuti arah diagonal, maka model regresi memenuhi asumsi normalitas dan Jika data menyebar jauh dari garis diagonal atau tidak mengikuti arah garis diagonal maka model tersebut tidak memenuhi asumsi normalitas.

Uji Multikolonieritas dilakukan untuk menguji apakah model regresi ditemukan adanya korelasi antar variabel bebas. Model regresi yang baik 
P-ISSN $2580-7781$

E-ISSN 2615 - 3238

seharusnya tidak terjadi korelasi diantara variabel independent saling berkorelasi maka variabel ini tidak ortogonal, yaitu variabel independen sama dengan nol. Multikolonieritas dapat dilihat dari nilai tolerance dan lawannya variance invlation factor (VIF). Tolerance mengukur varibelita - variabel independen yang terpilih yang tidak dijelaskan oleh varibel independen lainnya. Tolerance value $<0,10$ atau VIF $>10$ terjadi multikolonieritas. Tolerance value $>0,10$ atau $\mathrm{VIF} \leq 10$ tidak terjadi multikolonieritas.

Permasalahan yang akan dibahas adalah keputusan pembelian konsumen berdasarkan kegiatan promosi dan citra terhadap merek alat tulis faber-castell pada PT Mentari Sinar Abadi. Dengan menggunakan analisis regresi berganda karena variabel dependent dipengaruhi dua variabel independent, dengan rumus sebagai berikut:

$$
\begin{aligned}
& \hline \mathrm{Y}=\mathrm{a}+\mathrm{b} 1 \mathrm{x} 1+\mathrm{b} 2 \times 2+\varepsilon \\
& \hline \mathrm{Y}=\text { Keputusan pembelian } \\
& \mathrm{a}=\text { Bilangan konstanta } \\
& \mathrm{b} 1=\text { Koefisien promosi } \\
& \mathrm{b} 2=\text { Koefisien brand image } \\
& \mathrm{x} 1=\text { Promosi } \\
& \mathrm{x} 2=\text { Brand image } \\
& \mathcal{E}=\text { Standar eror }
\end{aligned}
$$

\section{HASIL PENELITIAN DAN PEMBAHASAN}

Kepeduliannya pada lingkungan hidup telah mengantarkan Count A.W. von Faber-Castell (Chairman, Faber-Castell Group of Companies) memperoleh penghargaan sebagai Eco Manager of the Year pada tahun 2008 oleh WWF (World Wild Foundation). Tentu kita semua sangat gembira dengan adanya pengusaha yang peduli terhadap lingkungan hidup. Berharap ke depannya nanti Faber-Castell dan banyak perusahaan lain menerapkan hal yang sama di belahan dunia manapun mereka mendirikan pabrik dan memperoleh bahan bakunya, seperti contohnya di Indonesia. 
P-ISSN $2580-7781$

E-ISSN 2615 - 3238

Baru-baru ini Faber-Castell Indonesia menggarap sisi akademik siswa sekolah, persisnya persiapan menempuh Ujian Nasional. Caranya, merilis portal LatihanUjian.com yang berisi prediksi Ujian Nasional. Keunikannya, portal yang memuat pembahasan atas soal-soal tersebut tidak hanya memberi evaluasi pada siswa tentang kekuatan, tetapi juga kelemahannya. "Ada umpan balik langsung dari portal pada siswa yang bisa dibantu orang tuanya. Tentu akan lebih baik kalau ada campur tangan guru," jelas Yandramin Halim, Managing Director PT Faber-Castell International Indonesia, sambil meresmikan portal latihanUjian.com $(26 / 3)$.

Sisi non akademik diperkuat secara bersamaan. Dari jumlah keseluruhan siswa yang gagal dalam Ujian Nasional, sebanyak 25\% tidak lulus karena persoalan non akademik. Misalnya, salah mengisi lembar jawab komputer atau menggunakan pensil yang tidak terbaca oleh pemindai. Maka, Faber-Castell pun menjamin bahwa pensil mereka pasti terbaca pemindai. "Produk pensil 2B memang diberi perhatian khusus. Kalau tidak, kami tidak hanya kehilangan bisnis, tapi siswa juga bisa tidak lulus," katanya menekankan.

Faber-castell sebagai merek dagang pensil hitam 2B nyatanya citra mereknya dapat diterima sekali dipasaran, ini terbukti beberapa kali faber-castell mendapatkan penghargaan mengenai brand dari beberapa lembaga independent yang ada, seperti dalam penghargaan TOP Brand Award Indonesia. Untuk mengenai merek berdasarkan top brand award, faber castell memiliki citra merek yang dapat diterima pada pasar konsumen alat tulis. Beberapa merek yang memiliki kualitas yang relatif sama dapat memiliki kinerja yang berbeda-beda dipasar karena perbedaan persepsi yang tertancap dibenak konsumen.

Oleh karena itu suatu merek yang dirancang perusahaan harus dapat memenuhi apa yang dibutuhkan dan di inginkan konsumen serta komunikasi dengan baik, sehingga pada saat konsumen membutuhkan produk tertentu, maka konsumen akan memutuskan produk dengan merek tersebut yang menjadi pilihan utama untuk dibeli. Merek bukanlah sekedar istilah, tanda, simbol atau kombinasinya. Lebih dari itu merek adalah janji perusahaan secara konsisten memberikan features, benefits, dan services kepada para pelanggan. 
P-ISSN 2580 - 7781

E-ISSN 2615 - 3238

Hasil Uji Validitas menunjukkan bahwa nilai $\mathrm{r}_{\text {-hitung }}$ validitas ke-32 item pertanyaan adalah lebih besar dari $\mathrm{r}_{\text {-tabel }}(0.242)$ sehingga dapat disimpulkan bahwa ke-32 item pertanyaan adalah valid.

Pada uji reliabilitas memperlihatkan bahwa ketiga variabel penelitian memiliki nilai r-hitung reliabilitas lebih besar dari 0.70, sehingga dapat disimpulkan bahwa ke 3 variabel penelitian adalah reliabel.

Tabel 1. Nilai Reliabilitas

\begin{tabular}{|c|l|c|c|c|}
\hline No & \multicolumn{1}{|c|}{ Variabel } & Cronbach Alpha & Koef Reliabilitas & Kesimpulan \\
\hline 1 & Promosi (X1) & 0.850 & 0.70 & Reliabel \\
\hline 2 & Citra Merek (X2) & 0.883 & 0.70 & Reliabel \\
\hline 3 & Keputusan Pembelian (Y) & 0.891 & 0.70 & Reliabel \\
\hline
\end{tabular}

\section{Normal P-P Plot of Unstandardized Residual}

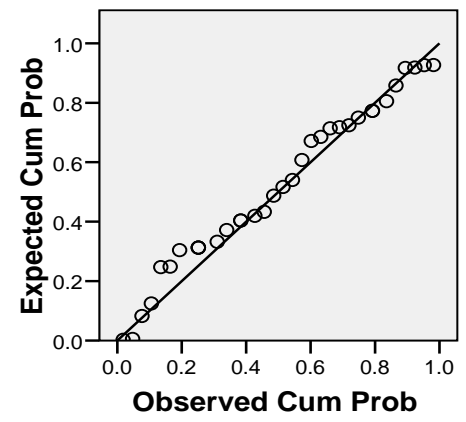

Gambar 3. Uji Normalitas

Grafik di atas memperlihatkan bahwa titik titik data tersebar di sepanjang garis diagonal membentuk simetris kiri dan kanan. Hal ini mengindikasikan bahwa data penelitian berdistribusi normal. Hal yang sama juga diprlihatkan oleh grafik histogram pada berikut :

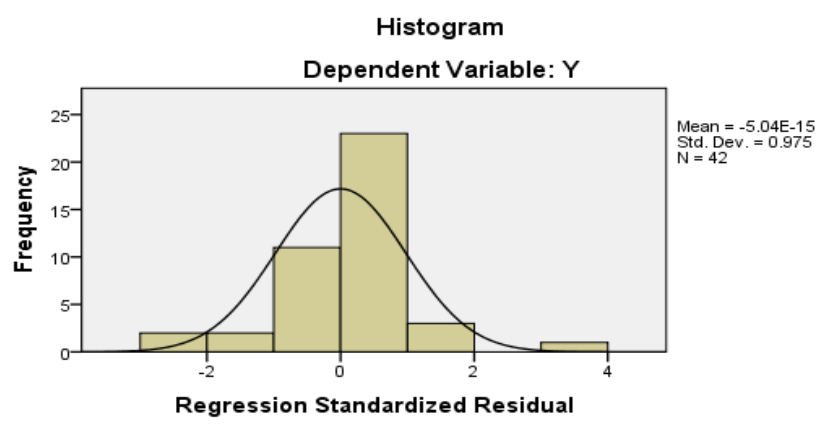

Gambar 4. Histogram Uji Normalitas 
P-ISSN 2580 - 7781

E-ISSN 2615 - 3238

Uji multikolinieritas yang dilakukan memperlihatkan hasil seperti pada tabel berikut:

Tabel 2. Uji Multikolinieritas

Coefficients $^{\mathrm{a}}$

\begin{tabular}{|ll|r|c|}
\hline \multirow{2}{*}{ Model } & \multicolumn{2}{|c|}{ Collinearity Statistics } \\
\cline { 3 - 4 } & & Tolerance & \multicolumn{1}{c|}{ VIF } \\
\hline 1 & Promosi & .755 & 1.325 \\
& Citra Merek & .755 & 1.325 \\
\hline
\end{tabular}

a. Dependent Variable: Keputusan Pembelian

Tabel diatas memperlihatkan bahwa nilai tolerance ke-2 variabel bebas $\mathrm{X}_{1}$ (promosi) dan variabel $\mathrm{X}_{2}$ (citra merek) secara berturut turut adalah 0.755 lebih besar dari 0,10 , dan nilai VIF adalah 1.325 lebih kecil dari 10 sehingga dapat disimpulkan bahwa data penelitian tidak mengandung gejala multikolinieritas.

Uji heteroskedastisitas bertujuan untuk menguji apakah dalam model regresi terjadi ketidaksamaan variance dari residual satu pengamatan ke pengamatan yang lain. Jika variance dari residual satu pengamatan ke pengamatan lain tetap, maka disebut homoskedastisitas, sebaliknya jika berbeda disebut heteroskedastisitas. Uji heterokedastisitas dalam penelitian ini dapat dilihat dari pola gambar scattterplot.

\section{Scatterplot}

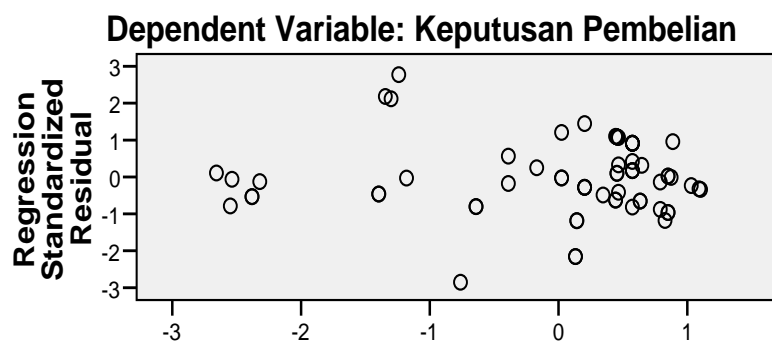

Gambar 5. Uji Heteroskedastisitas

Pola gambar scatterplot pada model penelitian ini dapat dilihat pada gambar diatas.

Grafik scatterplot menunjukan bahwa tidak terjadi heteroskedastisitas pada model regresi. Hal ini dikarenakan penyebaran titik-titik data yang tidak berpola.

Untuk mengetahui pengaruh masing masing variabel bebas terhadap variabel terikat Y (keputusan pembelian), dilakukan uji-t secara parsial dengan hasil seperti pada Tabel berikut ; 
Coefficients

\begin{tabular}{|rl|r|r|r|r|r|}
\hline \multirow{2}{*}{ Model } & \multicolumn{2}{|c|}{$\begin{array}{l}\text { Unstandardized } \\
\text { Coefficients }\end{array}$} & $\begin{array}{c}\text { Standardized } \\
\text { Coefficients }\end{array}$ & & \multirow{2}{*}{} \\
\cline { 2 - 5 } & \multicolumn{1}{|c|}{$\mathrm{B}$} & Std. Error & \multicolumn{1}{c|}{ Beta } & \multicolumn{1}{c|}{$\mathrm{t}$} & \multicolumn{1}{c|}{ Sig. } \\
\hline 1 & (Constant) & 1.766 & 3.322 & & .532 & .597 \\
& Promosi & .626 & .089 & .577 & 7.077 & .000 \\
& Citra Merek & .349 & .077 & .369 & 4.523 & .000 \\
\hline
\end{tabular}

a. Dependent Variable: Keputusan Pembelian

Promosi berpengaruh terhadap keputusan pembelian produk perusahaan Hal ini diindikasikan oleh nilai bahwa bahwa $t_{\text {-hitung }} \mathrm{X}_{1}$ (7.077) $>\mathrm{t}$ tabel $_{\text {tab }}$ (1.99) dan sig-p (0.000) $<0.05$. Citra merek berpengaruh terhadap keputusan pembelian konsumen pada produk perusahaan. Hal ini diindikasikan oleh nilai bahwa $t_{\text {thitung }} \mathrm{X}_{2}$ (4.523) $>\mathrm{t}_{\text {-tabel }}$ (1.99) dan sig.-p $(0.000)<0.05$.

Promosi dan Citra merek berpengaruh terhadap keputusan pembelian para konsumen terhadap produk perusahaan. Hal ini diindikasikan oleh nilai $\mathrm{F}_{\text {-hitung }}$ (67.703) $>\mathrm{F}_{\text {tabel }}(2.74)$ dan sig-p $(0.00)<0.05$.

Terdapat pengaruh variabel bebas terhadap variabel terikat, besarnya pengaruh variabel bebas terhadap variabel terikat adalah sebesar $0.669 \times 100 \%=66.9 \%$. Dengan kata lain, sebesar $66.9 \%$ variabel keputusan pembelian dapat dijelaskan oleh variabel Promosi dan Citra merek, selebihnya (33.1\%) dijelaskan oleh faktor-faktor lain yang tidak diteliti.

\section{KESIMPULAN}

Berdasarkan hasil analisis data tentang pengaruh Promosi dan Citra merek terhadap Keputusan Pembelian produk pada Perusahaan, dapat disimpulkan bahwa, Promosi berpengaruh terhadap keputusan pembelian produk perusahaan dan Citra merek berpengaruh terhadap keputusan pembelian konsumen pada produk perusahaan. Dalam hal ini juga dapat diketahu bahwa Promosi dan Citra merek berpengaruh terhadap keputusan pembelian para konsumen terhadap produk perusahaan. Oleh karenanya kepada Perusahaan, disarankan untuk lebih memperhatikan aspek aspek promosi dan Citra merek agar keputusan pembelian dapat lebih ditingkatkan. Kepada pegawai Perusahaan, disarankan untuk terus berusaha menciptakan citra merek yang jauh lebih baik agar keputusan pembelian dapat lebih ditingkatkan.

\section{DAFTAR PUSTAKA}

Alma, Buchai. 2007. Manajemen Pemasaran dan Pemasaran Jasa. Edisi 2. Bandung : ALFABETA

Alma, Buchari, 2011 Pemasaran dan Pemasaran Jasa, Alfabeta, Bandung. 
Andrianto, N HendradanIdris. 2013. Pengaruh Kulaitas Produk, Citra Merek, Harga Dan Promosi Terhadap Keputusan Pembelian Mobil Jenis MPV Merek Toyota Kijang Inova Di Semarang. Jurusan Manajemen Fakultas Ekonomi dan Bisnis Universitas Diponegoro, Volume 2, Nomor 3, Tahun 2013, Halaman 1-10. Tanggal Akses 10 November 2015

Kasmiir.2006 Kewirausahaan. Jakarta : PT Rajagrafindo Persada

Kotler, Philip dan Amstrong.2007. Prinsip - Prinsip Pemasaran Edisi Kedelapan. Jakarta :Erlangga

Kotler, Philip dan Amstrong , 2008. Prinsip - Prinsip Pemasaran ( Edisi 12 Jilid1). Jakarta :Erlangga

Kusnedi.2008. Model - Model Persamaan Struktural Satu dan Multi group Sampai Dengan LISREL Bandung : ALFABETA

Lembang, Rosvita, 2010. Analisa Pengaruh Kualitas Produk, Harga, Promosi, dan Cuaca Terhadap Keputusan Pembelian The SiapMinum Dalam Kemasan Merek The Botol Sosro (Studi Kasus Pada Mahasiswa S1 Fakultas Ekonomi Universitas Diponegoro). Skripsi. Fakultas Ekonomi Diponegoro, Semarang.

Lupiyoadi, Rambat dan Hamdani .2008. Manajemen Pemasaran Jasa Teori dan Praktek .Jakarta: Salemba 4

Mulyadi, Dedidkk. 2012.Analisis Merek Terhadap Keputusan Pembelian Kartu Perdana As Di SMA N 4 Karawang. JurnalManajemen, Vol. 10, No 1, Oktober 2012, Hal 993 - 1001. Tanggalakses 10 Nopember 2015

Schiffman dan Kanuk. 2009. Perilaku Konsumen. Edisi 7. Jakarta: Indeks Sugiono.2012. Statistika Penelitian. Bandung: CV ALFABETA

Purwanto. 2008 Metodologi Penelitian Kuantitatif untuk Psikologi dan Pendidikan, Pustaka Pelajar, Yogyakarta.

Purwanto. 2008 Metode Penelitian Kuantitatif Kualitatif dan R\&D, Alfabeta, Bandung.

Swastha, Bashu, Ibnu Sukotjo, 2010 Pengantar Bisnis, Liberti, Yogyakarta.

Tjiptono, 2008. Pemasaran Strategik. Yogyakarta : AFABETA 